\title{
Exocrine Pancreatic Cancer pT1a TNM
} Finding v8

National Cancer Institute

\section{Source}

National Cancer Institute. Exocrine Pancreatic Cancer pT 1a TNM Finding v8. NCI

Thesaurus. Code C134890.

Exocrine pancreatic cancer with tumor measuring $0.5 \mathrm{~cm}$ or less in greatest dimension. (from AJCC 8th Ed.) 